\title{
DE90 013640
}

\section{HIGH-RESOLUTION SIMULATION OF FIELD EMISSION*}

\author{
W. B. HERRMANNSFELDT
}

Stanford Linear Accelerator Center

Stanford University, Stanford, California 94309, USA

REINARD BECKER

University of Frankfurt, D-6000 Frankfurt am Main, W. Germany

IVOR BRODIE, ARNE ROSENGREEN, and C. A. SPINDT

SRU Intemational, Menlo Park, Californis 94025, USA

\author{
Contribuled to the Third International Conference on Charged Partiele Beame, \\ Toulouse, France, April 24-27, 1990
}

\section{DISCLAIMER}

This report was prepared as an accounl of work sponsored by an agency of the United States Government. Neither the United States Government nor any agency thereof, nor any of their employes, makes any warranty, express or implied, or assumes any legat liability or responsibility for the accuracy, completeness, or usefulness of any information, apparatus, product, or process disclosed, or represents that its use would not infringe privately owned rights. Reference herein to any specific commercial product, process, of service by trade name, trademark, manufacturer, or oiherwise does not necessarily constitute or imply its endorsement, recommendation, or favoring by the United States Government or any agency thereof. The views and opinions of authors expressed herein do not necessarily state or reflect those of the United States Government or any agency thereof.

-Work supported by US Department of Energy contract DE-AC03-76SF00515 (SLAC).

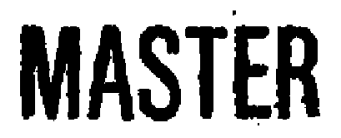




\section{Abstract}

Iligh-resolution simulations of feld emission electron sources have bern made using the clectron optics program EGN2. Electron emission distributions are made using the Powler-Nordlicim equalion. Mosh resolution in the range of $1.5 A$ is required to adequately model gurface details that can result in emission currents in the range found experimentally. A typical problem starts with mechanical details with dimensions of about $1 \mu \mathrm{m}$. To achieve ligh resolution a new boundary is defined by the tip, a ncarby equipotential line, and a pair of field lines. The field lines (one of which is normally the axis of symmetry) define Neumann boundaries. This new boundary is then used by the boundary prepronassor POLYGON to create an enlarged version of the problem, typically by a factor of ten. This process can be repeated until adequale resolution is obtained to simulate surface details, such as a microprotusion, that could sufficiently enhance the surface electric fields and cause ficld emission.

When simulating experimental conditions under which emission of several microamperes per tip were observed, it was found that both a locally reduced work function and a surface protrusion were needed to duplicate the experimental results. If only a local region of reduced work function is used, the area involved and the extent of the reduction both need to be very large to reproduce the observed emission. If only a surface protrugion is used, it is possible to get the observed emission current with a reasomable protrusion of length a few times radius, but then the resulting bearn spreads over a very large solid angle due to the strong local radial electric fields. 


\section{Introduction}

This paper bas two objectives:

(1) "o illustrate the teciniques of nagnifying the details of a region being simulaterd for Poisson's liquation, and sulsatguent raytraciug to the extcont. necess. sary to dirertly apply the Fowler Nordheim equnation [1] to detrentue emission density and distribution.

(2) Th test the predictions of different assumed surface slıapes and work function distributions te find results that agree with obsurvations.

'I'he experimental conditions that wen: simulated are similar to the gated field cmitters ured by Spindt [2] et al. Typically they find emission of a few mieroamperes pet tip with about $100 \mathrm{~V}$ on the gate. The observed eurrent distribution is uneven, learling to the conclusion that a number of small regions are emitting anomalously rather than in a gonerally uniform emission from the entire tip surface.

The simulations were made with the SLAC Electron Trajectory Program E.GN2 [3] as converted to the language $C$ and run on an tBM-type PC. The boundary inpul preprocessor program POLYGON [4] was used to define the boundaries and to perform the necessary magnifications. POLYGON contains a wzoom" feature that can expand and translate a region of a problem into a boundary dataset that contains the new boundary input data. Inputs co POLYGON are comprised of a combination of manually punched poirts, and data generated by EGN2 from the previous problem.

\section{Techniques of Enhancing Resolution}

This section is intended to demonstrate the nethods by which successively higher resolution can be used to find the field distribution on the surface of a small point. A feeling for the magnitudes involved can be olstained by considering tlat the typical 
dimensions of the gated fiedd emitlers are about 1 mu ju both the height of the emitter and the radius of the hole. 'The resolution needed to find the surface fields to the: necessary accuracy is about $10^{-10} \mathrm{~m}$; thus to simulate only the lirst tew mirrometers of the beam, onc would rexuluire tnuch more than $10^{8}$ mesh units.

The requirement for surle high resolution stems from the uevel to be able to smoothly interpolate from the mearest mosh point to the surfacre along the smallest detaile deemed significant. 'The field-solving and partial routines are typically uecurale to second-order in the spatial courdinates. Hecause potentials change wo rapidly in the immediate proximity to a sharp point, it is necessary to have a mesh small comparch to the dimensions of the point.

The gated field emillem typically resemble those shown in the microphotograph of fig. 1. In fig. 2 a single point and a small gegment of the gate: are shown with all extension to the right to simulate the presence of a drift region. In typical tests this drift region is about $1 \mathrm{~mm}$ long and is terminated by a surface abont $1 \mathrm{kV}$ above the gate potential. The right side of fig. 2 is terminated by an equipolential surface to maintain a uniform field of $1 \mathrm{kV} / \mathrm{mm}$ in the drift space. As noted on the figure, the resolution used is $0.05 \mu \mathrm{m}$ and the gate voltage is $100 \mathrm{~V}$. The upper houndary is a Neumann boundary in both the zone between the base and the gate, and in the drif region. The limited Neumann condition used in EGN2 is that the normal field component is zero.

Figure 2 shows several equipotential lines and a single ficld line from the cone to near the inner edge of the gate electrode. The plan is to form a new boundary using the field lipe as a general Neumann boundhry and an equipolential line as a "virtual anode." The method by which output from EGN2 is specificd for POLYGON is discribed in sec. 3. In fig. 3 the boundary found from fig. 2 has been expanded by a factor of ten by using the zoom feature of POLYGON. Again a single field line has been generated with the 
intention of cr at: ing anolher expanded boundary. Figure 4 shows the next enlargement. again by a factor of ten from the previous atage. The boundary near the tip of fig. 4 shows a snall bump, which will be enlarged in detail in the next magnification. Again using the single field line from fig. 4 and the second of the two equipotential lines that are very close together, a nww boundary dataset is generated, this time with an enlargement factor of tive. Figure 5 shows the final stage of enlagement including a small bump with a radius of five mesh units, where the mesh is now $1 \dot{A}$.

The trajectories shown in fig. 5 were generated using the GENCARD feature of EGN2. In this mode the user specifies the starting coordjnates of a particle, and EGN2 calculates the rest of the initial conditions including the current assigned to that particle. By specifying the work function and the field enhancement factor $\beta$, the user signals EGN2 to empry the de formulation of the Fowler-Nordheim equation. An arbitrary decision has to be made by the user to determine the maximum angle, measured from the axis along the aurface of the bump, for which emission will be calculated. Emission drops very quickly as a function of surface field with the Fowler-Nordheim equation, but the current is also proportional to the annular area assigned to each particle, so that trajectories emitted at fairly large angles contribute significantly. The trajectories in fig. 5 were limited to those with $50 \%$ or more of the peak eurrent per ray. Note that the positions were chosen with equal spacing betwern rays.

The problem of determining the actual beam trajectories for the entire system now simply requires going back through the sct of enlarged figures, sequentially making the outpul of each problem be the input data for the next stage. EGN2 needs only to know the ratio of the scale factors and the offsel of the origin to transform the oulput data from one atage to the iuput for the next. 
Accordingly, fig. 6 shows the trajectories using the fual conditions from fig. 5 as initial conditions. Figure 7 ukes the ontput from the run in fig. 6 for inilial conditions. Finally, fig. 8 uges the final conditions from fig. 7 to show the trajectories through the entire length of the originsl configuration.

\subsection{Emission Models}

It is beyond the scope of this paper to study the various eniusion models. How. ever, it is interesting to consider that these high-resolution simulations may give some information as to which model is correct. Two very simple models are:

(1) a whisker or bump, as was shown above, causes field endsancenent sufficient to give the observed current; and

(2) a surface contaminant such as an oxide layer causes a local reduction in the effective work function, as described by Latham [5].

It appears quite clear that the field enhancement due just to the sliape of the shary" field emitters is not sufficient to cause significant emission, willont one or both of the above conditions or some other mechanism to enhance the emission. In the following paragraphs we will consider the trajectory implications of the two options, and finally we will propose that the actual mechanism may require a combination of both models.

In a uniform field the field enhancement at the tip of a hemispherical bunp is it factor of three. This enhancement is independent of the radius of the bump. In fig. 9 we show the surface field distribution both for the bump in fig. 5 and for a bump with double the radius. Although there is some lack of smoothness in the plots due to the mesh structure, the obvious regularity and the fact that both curves have the samenaximum demonstrate the accuracy of the method.

The obvious characteristic of emission from a stmall butnp or whisker is that the beam spreads quickly into a large angular cone. In our simulation we can best denl with 
a bump on the axis, while in practice there would more likely be weveral bumjes senttered over the surfare of the point. Thers cannot be a targe number of bumps, or the surface wouli again become smooth, but 10 to 500 bumps of various sizas serms poskilile. 'J'he' enission pattern shown for one buup would then lse repeated and overlail a muminer of times, This would result in a large, fairty uniformly illuminated region of the anode with an intensity pattern that would generally resemble a Gaussian curve. The angular divergence of the spot at a distance from the tip is about ten degrees, as shown in fig. 8 .

Since the bump is of atomic dimensions, it could be that electrons prefer to tunnel from the lip of the bump; in eitect, the work function varies around the stom, being at its lowest at the tip. This is a quantum mechanical problem that needs to be addressed analytically [0].

Short whiskers with hemispherical ends, at shown in fig. 10, have slightly larger divergent angles, primarily because the emission is initiated at lasger angles since the enhanced field continues around the point tarther. Table 1 shows the peak field, milted current, and divergence angle for various whisker lengths, where the work function is $4.5 \mathrm{eV}$ in all cases. In praclice, the obeerved angle of divergence is about two degrecs, and is smaller for whiskers with adsorbed barium atoms than for uncontaminated whiskers (7).

If we consider that a small region with atomic dimensions of a few angatroms inight emit with an anomalously low work function from s smooth microsurface, then emission from the tip would appear as modeled in fig. 11. A reasonable number of such sites could be emilting, causing an emission pattern with numerous hot spots. Using a spot about $6 A$ in diameter, as shown in fig. 11, the emission was about $0.1 \mu A$ with a work function of only $2.0 \mathrm{eV}$. A stalistically significant number of such sites-perlaps ten or more-would be required per tip in order to account for the observed emiasion, or indend to assure that there would be any emission at all. 
If as suggested above a lew geometric enhancemunts also were to have an ancmalowsly low work function megenent, then it is not necessary that the work function he extremcly low. 'l'hese enhanced regions must in geseral be somewht larger than the emitting spot, or again the emission paltern would be very spread out. There conld nol lne very unny such regiona per tip, sitmply beratise of the lask of room, but morl tip conld have more than one sitc. 'l'he gain of thres! in lield strength greatly angmunts the entission function so that, for example, in the cruse of the nodel shown in fig. 12 with a I $\mathrm{nm}$ radius bump and a work finction of $3 \mathrm{eV}$, the emission is about $1 \mu \mathrm{A}$. Thu, beam from fig. 12 was carried through the intermediate stages, as demonstrated previously, and finally gave the result shown in fig. 13. The spread is still significant dur to the small radius of the bump, but the extent of it is reduced to about five degrexs. As the radius of the small bump is increased, the divergence approarhes the small spread shown in fig. 11, which would also agre with the observation of small hot spots with two-degree divergence.

\section{EGN2 Techniques}

In this section we describe some of the special techniques that were used to make the high-resolution simulations with EGN2. The reader should refer to the Instructions for EGN2 and POLYGON for a more general applicalion of the data described here.

For the output shown in fig. 2, ECN2 was asked for the equipotentials to be iniliated in the uniform ficld region at $R=30$, by setting $E Q U 1 P R=30$. EGN2 was also asked for a single ficld line, selected to start at a point along the cone such that the line would terninate near the end, to the gate electrode. Field lines in EGN2 are obtaind by forcing the momentum of the trajectorieg to be resel to zero after cad iterative step. 'J'his condition is signaled to BGN by setting the particle mass to a negative number: u.g., MASS=-1. Data for a trajectory is saved in the input format for POLYGON if 
MASS=-1 and IPBP = 1, assuming only one trajectory. 'The IPLP signals EGN2 to record all the data for every step of up to six particles with ray numbers given in the format IPBP $=n 1, n 2$, etc. Similarly, the coordinates for the equipotential line is saved if the line is called for by the parameter EQZLST, which is the Z-coordinate of a point at R=EQUIPR. Finally, all this dnta is saved in the output file, which can be printed or scanat on a monitor. Aa editor can be used to extract the necessary segmonts of the field line and the equipotential line to form the boundary input data for POLYGON. As an added curvenience, the data for a field line and an eqipotential line (if called as described above) are saved instead in a separate file if a file designation is placed in the sixth position of the command line calling EGN2. The command line has the following format: EGN2 inputfile outputfile plotfile cardfile binaryfile polyfile.

The choice of the starting points for the equipotential line and the field line determines the directions for these lines, and thus the sequence of points. They must be specified so that the lines go in the right direction (which is why EQUIPR=30 was used) to avoid a large editing job inverting the sequence of these points. Note that equipotential lines stast both "up" and "down" when they are called. "The editing task for preparing the new dataset for POLYGON consigts of deleting the rest of the boundary from the initial input dataset for POIYGON, saving only the part needed (in this case only that part for the tip of the cone), and then adding in the desired seguent of the field line and the equipotential, respectively. Some care is needed at the intersection of these two segments to avoid confusing POLYGON. The last line of POI.YGON input. consists of four numbers: RO, ZO, SFR, and SFZ where $\mathrm{RO}$ and $\mathrm{ZO}$ define a new origin and $S F R$ and SFZ define the zoom scale factors. In this casc we used $S F R=S F Z=10$ and $\mathrm{RO}=0$. The number $\mathrm{ZO}$ was chosen so as not to waste too much space (equal to the Z-value of the starting point of the field line in this case) only because the plots get strange looking if the origin is far from the region of intereat. The $\mathrm{ZO}$ value will be 
needed agnin when the coordinates are shifted back, to perunit continuations of the runs for ray tracing. Thus it is useful to record the ZO's and helpful to use simple numbres. Note that the transformation equations are of the form:

$$
\text { ZNEW }=(2 O L D+Z O)^{*} \mathrm{SPZ}
$$

In some cases there is not enough delail in the input boundasy get to POI.YC:ON to result in an adequate result. In these cases a simple siratagem is to use the filr PANZOOM.IN, which POLYGON creates to run wiblh the transforned input data. This lile can be edited to be an ordinary POLYGON input file, with adequate detail but without the PANZOOM dala line. This trick was used in the two enlargements of a faclor of ten, as slown earlier.

\section{Conclusions}

Enhancements to the electron optics program EGN2 have enabled it to be used for high-resolution simulations of electron trajectorics from field-emitting points will radii of a few hundred angstroms, It is anticipated that this method of simmlation will prove useful for testing hypotheses for the origination of field emission from very sharp tips, which is important for vacuum microelectronic devices [8] (including tuntıeling microscopes) and for the design of electrostatic lenses used with such devices. An cxample for the use of such a lens with a field emitter is shown in fig. 14 .

To simulate the observation that the emission fron such tips actually comrs Irom one or a few atomic sites $[2,7\}$, it was postulated that the localized emission was eitlere dlut to field enlaucement by a single protruding atom, or by the lowering of the work function at a given site due to a single nonprotruding impurity atom imbedded in the surfincs. Using the Fowler-Nordheim theory and assuming a unilorm work function around ats atomic bump, a divergence angle of ten degrees or nore is predicted. For the imberdidet 
alom of low work function, an angular sprend of abont two degrees is predirled, in snbstantial agreenent with observations where the divergence angle appears to vary with the type of atom from whence the electrons are streaning [7]. Combining the imbedded atom with a small bump gives enhanced emission with divergence angles that are between the two extremes described here. Clearly, it may be extenting the fow Nordheim theory beyond its scope to apply it direetly to atomic sites [6], but it shonid be straightforward to apply any new developments in tunncling theory to this computer model. 


\section{References}

[1] R. H. Fowler and I. W. Nordheim, Proc. Roy. Soc., A119 (1928) 173.

[2] C. A. Spindt, I. Brodie, L. Humphrey, and E. R. Weskerberg, J. Appl. Mhys. 47 (1976) 5248 .

[3] W. 13. Herrmannsfeldt, EGUN-- An Electron Optics and Gun Design l'rogratt, SLAC Report-331 (1988).

[4] R. Becker, Nucl. Instrum. Methods B42 (1989) 162.

[5] R. V. Latham, High Voltage Vacuum Insulation: The: Physical Basis (Ararlomiv Press, 1981).

[6] R. H. Cutler, T. F. Peuchtwang, 2. Huang, and T. Sullivan, Thenneling Throry and Vacunm Micnelectronics, in American Institute of Phytics Confernence Serirs 9? (1989) 121-123.

[7] 1. Brodie, "The Visibility of Atomic Objects in the Field Electron Microsrope," in Swi face Science 70 (1978) 186-196.

[8] Americun Institute of Physics Conference Series 99 (1989). 
Table 1. Emission from Whiakers.

\begin{tabular}{llcccc}
\hline Length/radius & 0 & 1 & 2 & 3 & 5 \\
\hline Peak field $\left(10^{8} \mathrm{~V} / \mathrm{cm}\right)$ & 0.5 & 0.68 & 0.84 & 1.02 & 1.3 \\
Emission $(\mu \mathrm{A})$ & 0.00056 & 0.054 & 0.53 & 2.6 & 18.3 \\
Diversion (degrees) & 9.7 & 16.5 & 18.2 & 20.1 & 23 \\
\hline
\end{tabular}




\section{Figure Captions}

1. A microphoiograph of a gated field emitter array.

2. The EGN2 model of a gated field emitter with a mesh urit of $0.05 \mu \mathrm{m}$.

3. Enlarged segment from fig. 2 with a mesh usit of $5 \mathrm{~nm}$.

4. Enlarged segment from fig. 3 with a mesh unit of $5 \stackrel{A}{ }$.

5. Enlarged segment from fig. 4 with a mesh unit of $1 A$. Emission calculations made using the Fowler-Nordheim Equation.

6. Particles from fig. 5 are reinjected into the next larger-scale segment.

7. Particles from fig. 6 are reinjected into the next larger-scale segment.

8. Particles from Fig. 7 continue through the original configuration.

9. Electric field around the $0.5 \mathrm{~nm}$ bump ohown in fig. 5 and also for the $1.0 \mathrm{~nm}$ radius bump shown in fig. 12 .

10. Emission pattern from a whisker with length/radius $=3$.

11. Emission pattern from a small region of a smooth surface.

12. Emission from a small area on the tip of a $1 \mathrm{~nm}$ radius bump.

13. Beam from fig. 12 transported with a divergence angle of about five degrees.

14. Field emission tip with a focusing electrode to produce a parallel beam. 


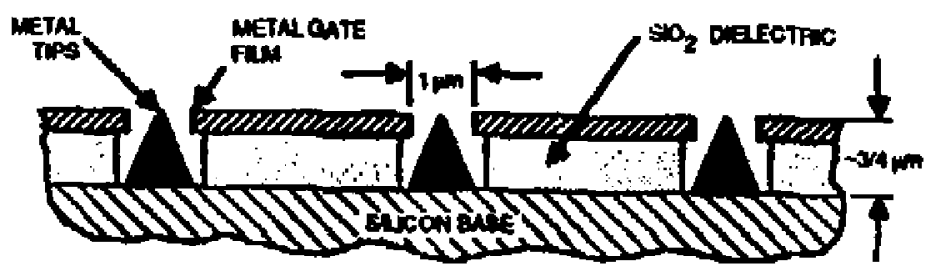

1torts-1

6) SchEMatic of A EHHot CAlHoOe AnhaY

8

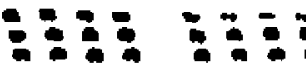

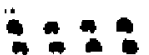

$\div \div$

6000

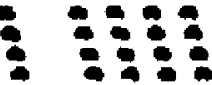

$=16$

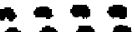

10

$-6$

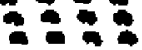

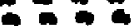

12

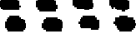

16

$\rightarrow 0$

$-4$

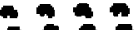

$-0$

$=$

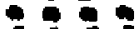

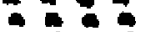

145

$-10$

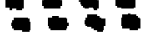

65

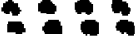

$-1$.

$-6$

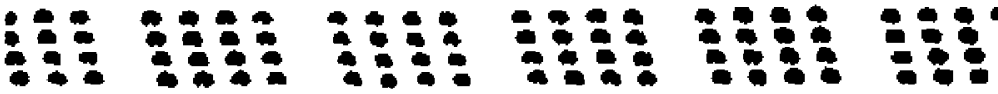

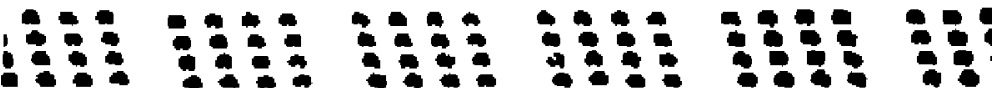

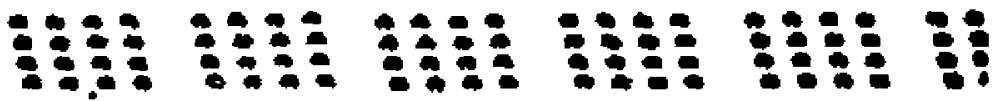

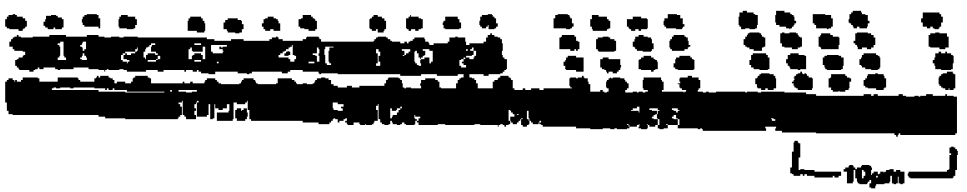

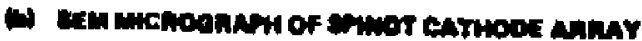

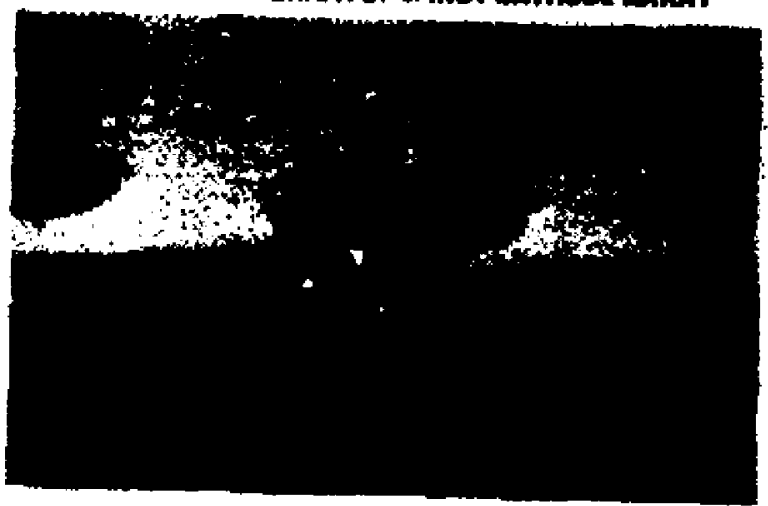

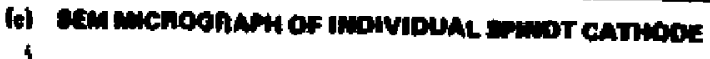

Fig. 1 


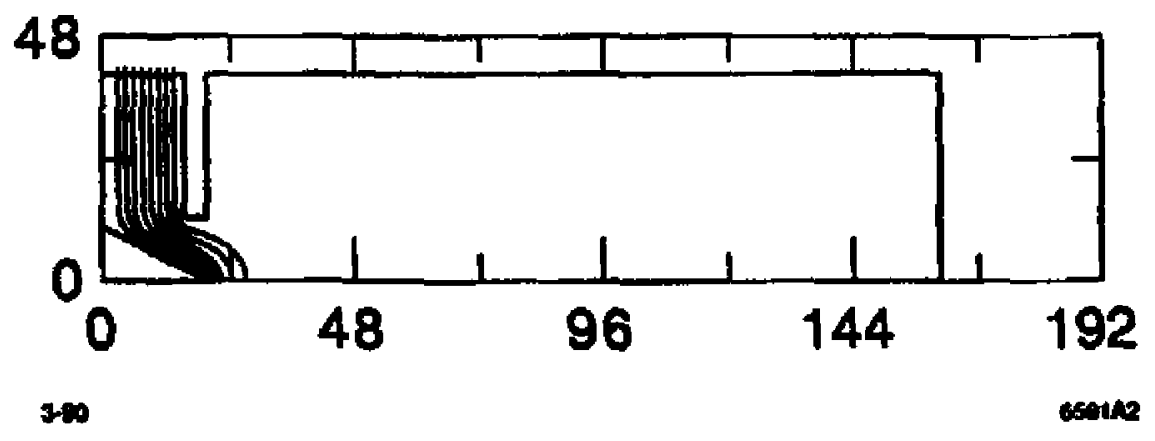

Fig. 2 


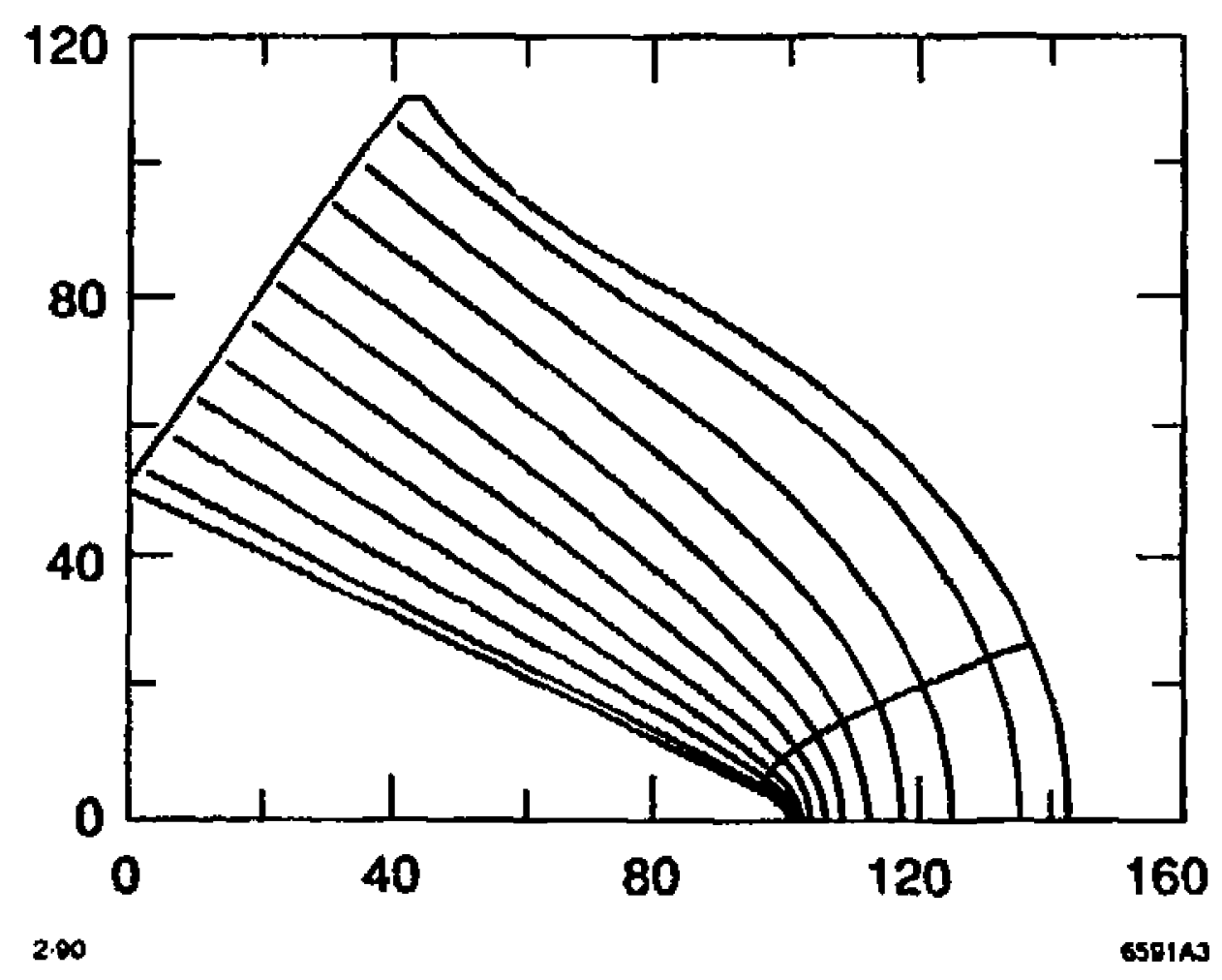

Fig. 3 


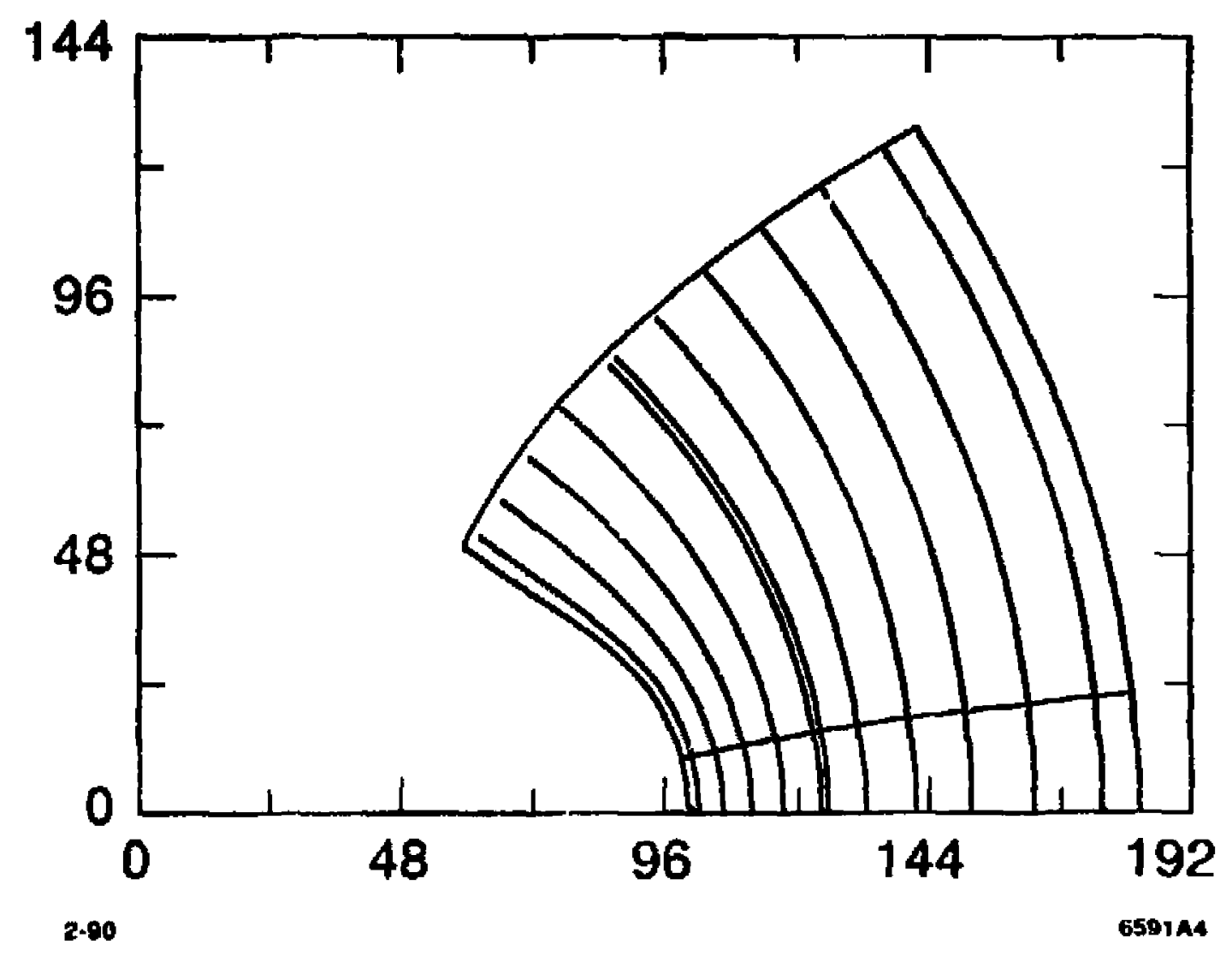

Fig. 4 


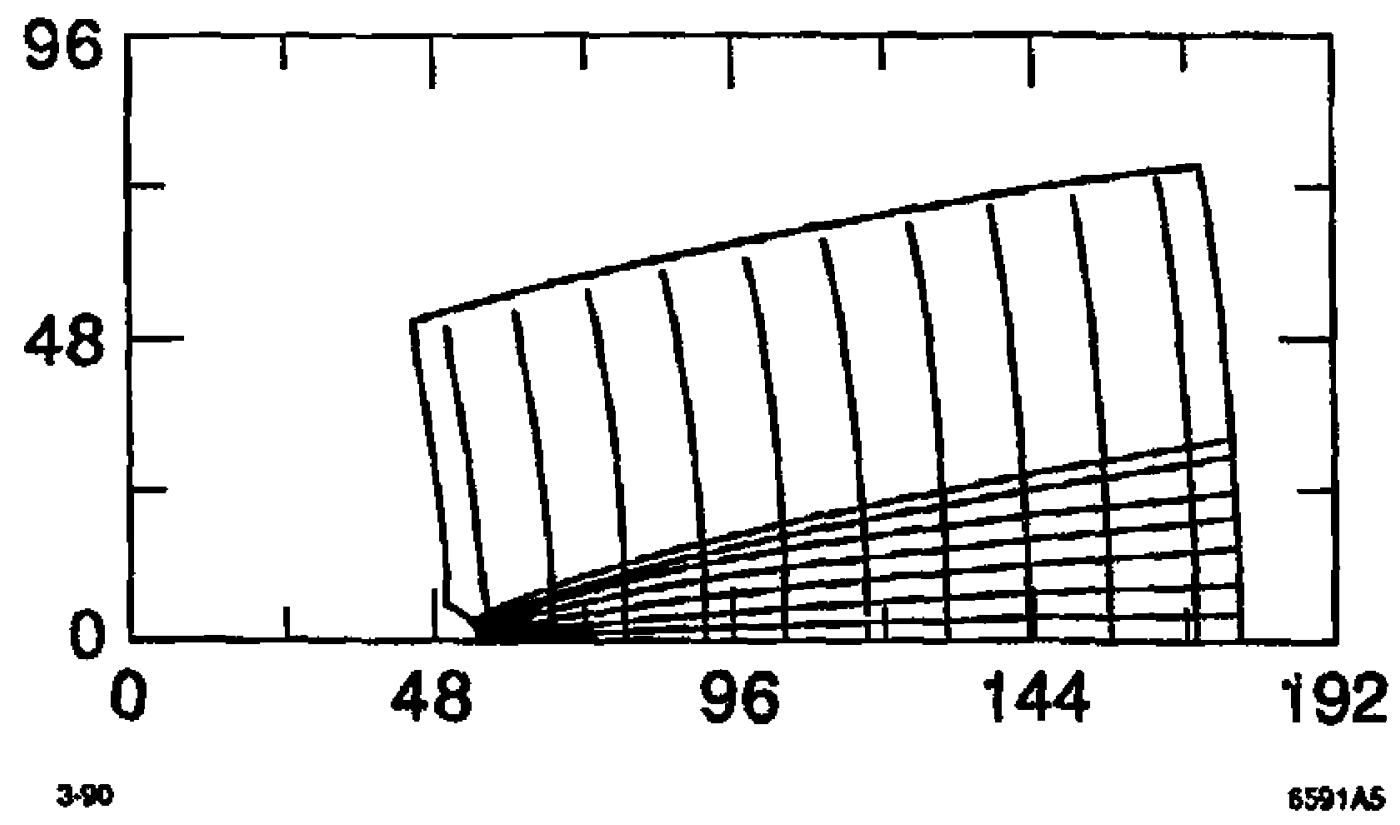

Fig. 5 


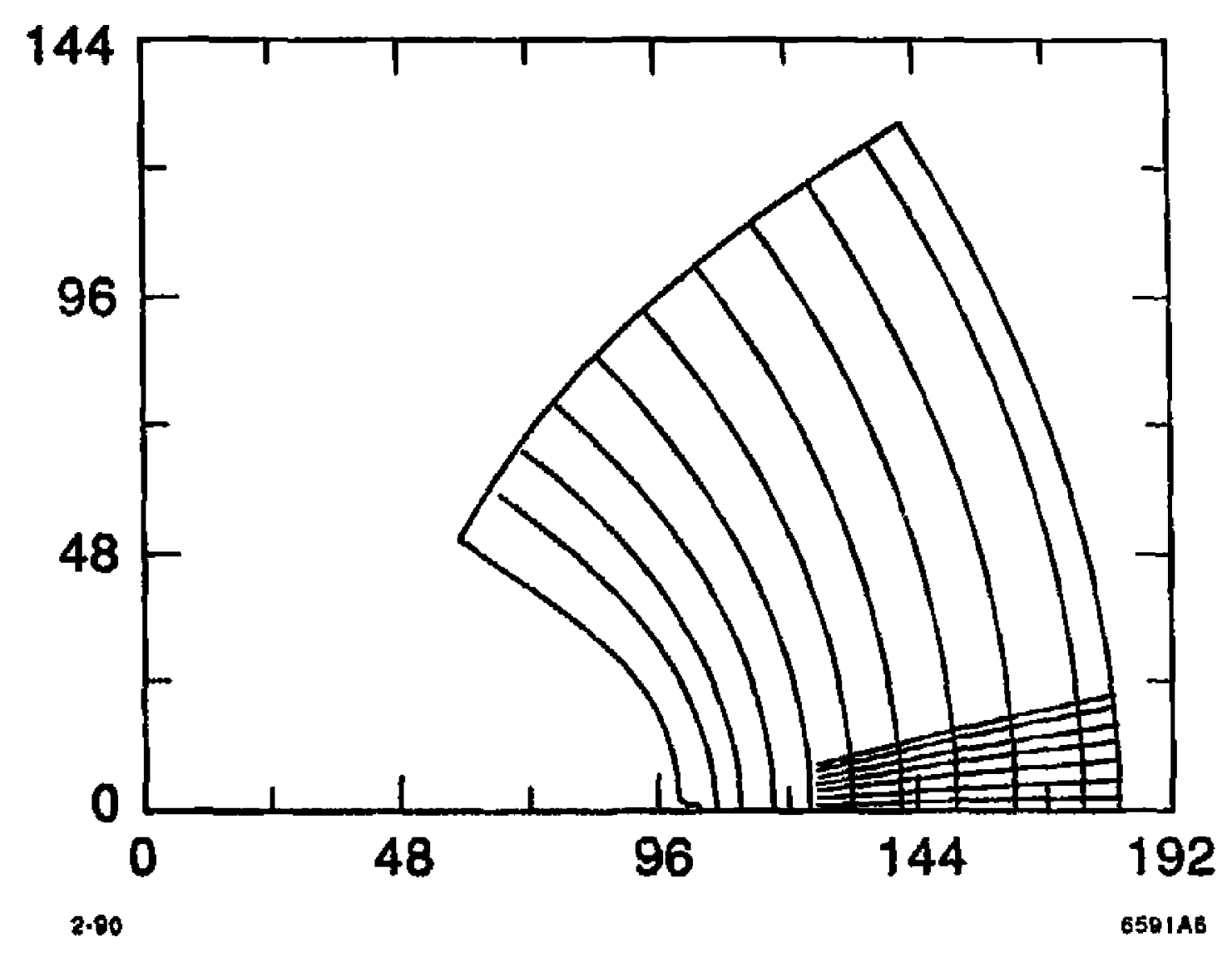

Fig. 6 


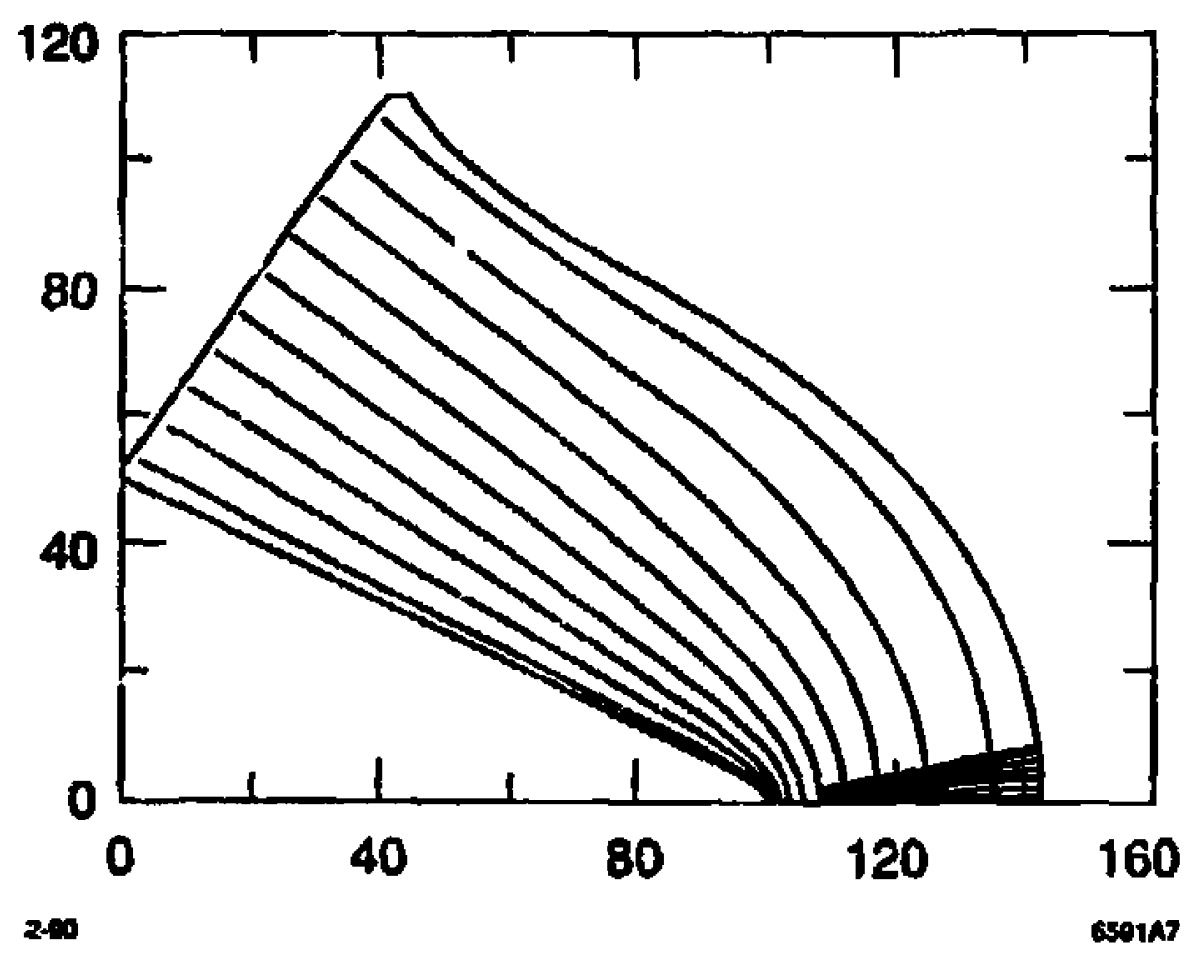

Fig. 7 


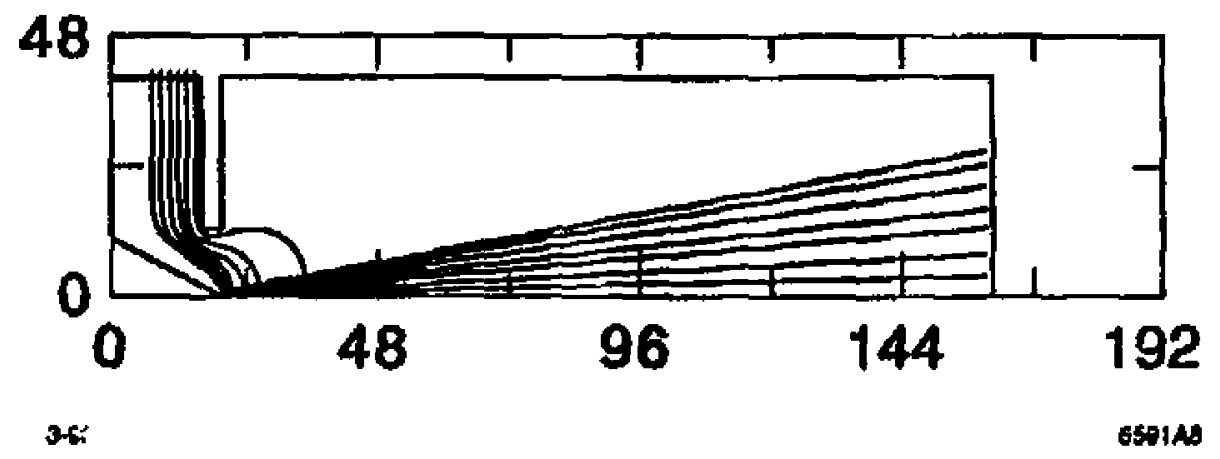

Fig. 8 


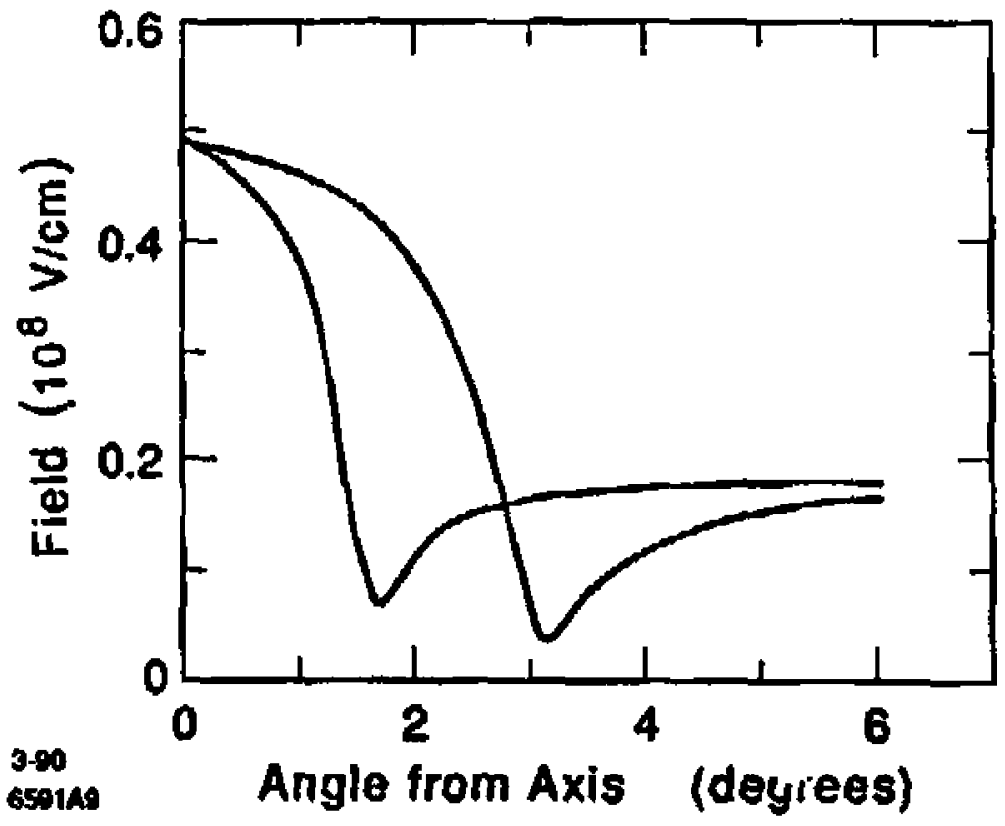

Fig. 9 


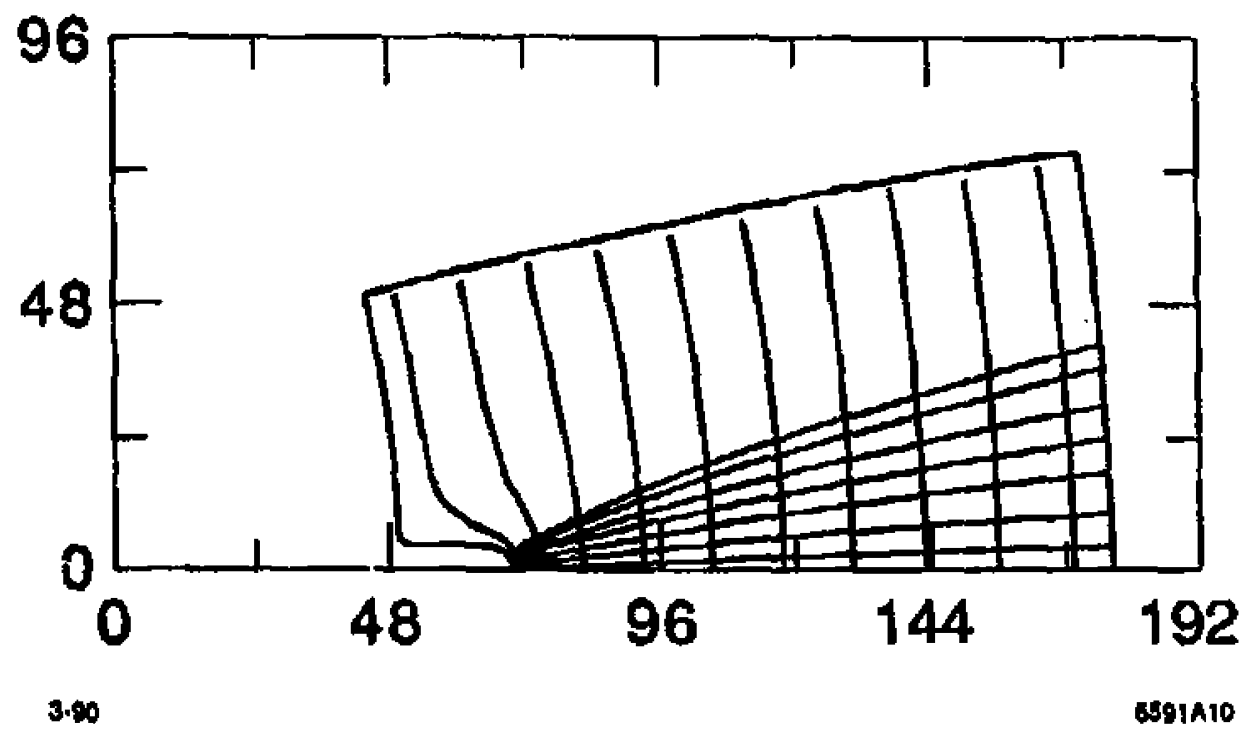

Fig. 10 


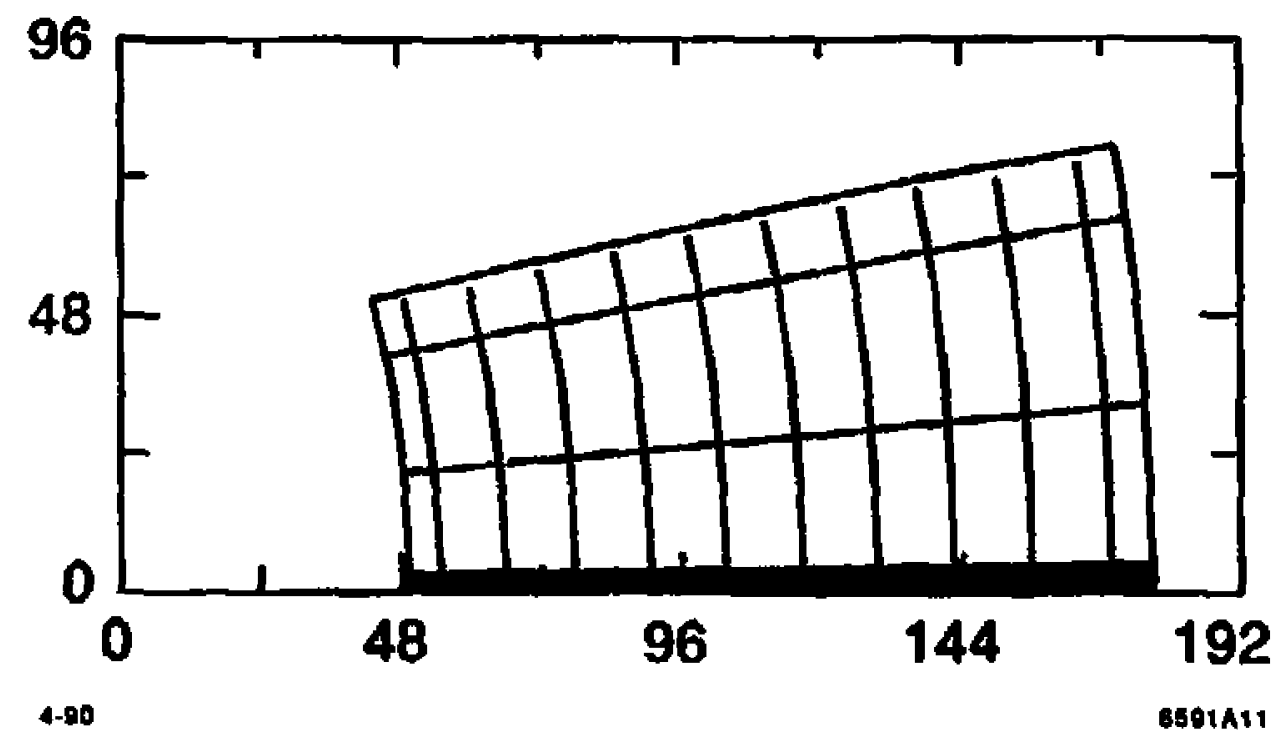

Fig. 11 


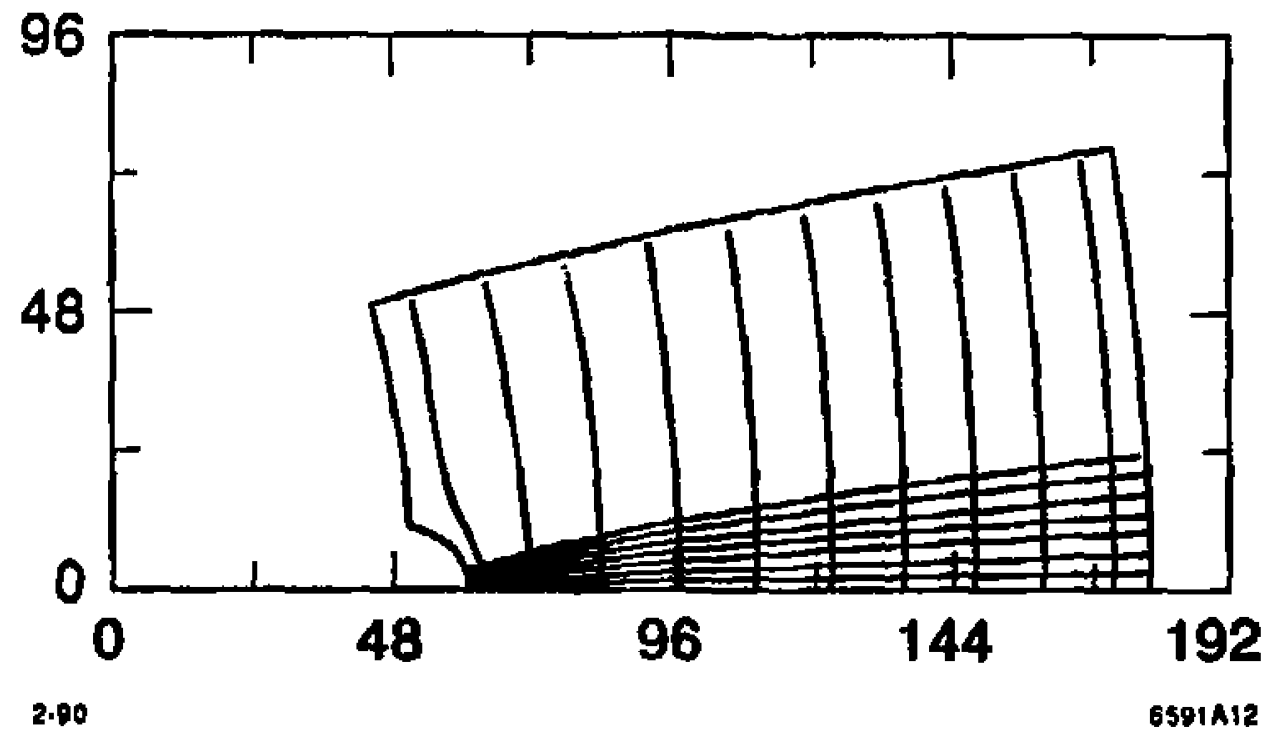

Fig. 12 


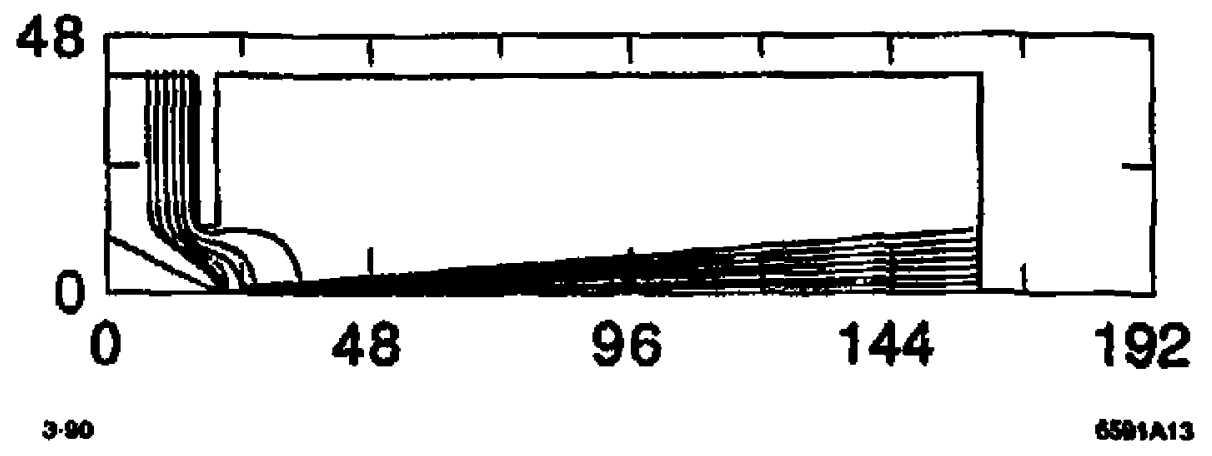

Fig. 13 


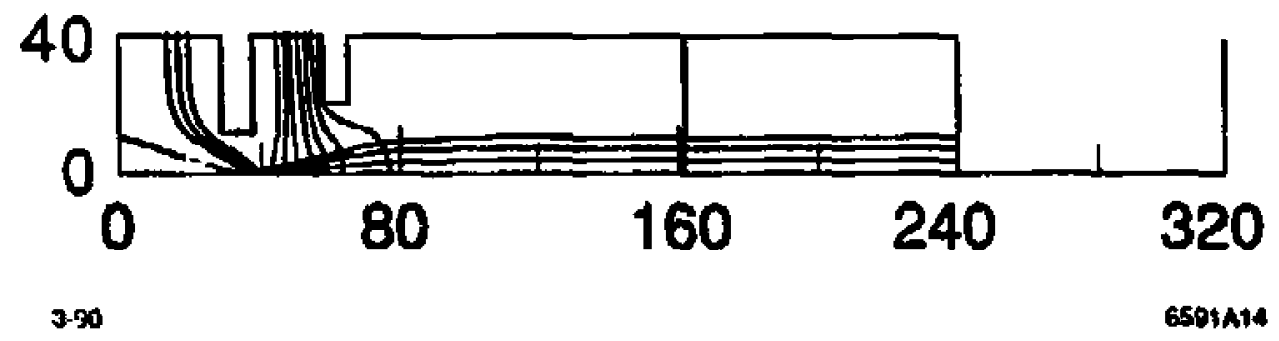

Fig. 14 